\title{
Novel Sophomore Assessment Modeled after the F.E. Exam
}

\section{Dr. Breigh Nonte Roszelle, University of Denver}

Dr. Breigh Roszelle completed her undergraduate degree in Mechanical Engineering at Colorado State University in 2006. She then continued in academia, completing her Masters and PhD in Bioengineering at The Pennsylvania State University. At Penn State Breigh worked in the Artificial Heart Lab, her research focused on studying the biofluid mechanics associated with the development of a pediatric ventricular assist device. After completing her $\mathrm{PhD}$ in 2010, Breigh came to Arizona State University to work as a post doc in the Image Processing Applications Lab. In 2013 she became a Teaching Assistant Professor in the Department of Mechanical and Materials Engineering at the University of Denver. Here Breigh teaches courses in the fields of thermodynamics, fluid mechanics, heat transfer, biofluids, and introduction to engineering. Her educational research interests include first-year engineering experiences, engineering assessment, and active learning pedagogy.

\section{Dr. Matt Gordon P.E., University of Denver}

Dr. Matt Gordon is Professor and Chair of the Department of Mechanical and Materials Engineering. His research areas include numerical and experimental plasma physics, chemical and physical vapor deposition, electronic packaging, and bio-medical engineering. He has supervised to completion $26 \mathrm{MSME}$ students and $5 \mathrm{PhD}$ students. Publications include 1 book chapter, 32 journal publications, 47 refereed conference proceedings, 29 non-refereed publications, and 27 non-refereed presentations. He is responsible for funds as PI or Co-PI from 52 separate proposals totaling almost $\$ 6,500,000$. Courses taught include undergraduate finite elements, thermodynamics, fluid dynamics, heat transfer, and engineering economics and ethics, and graduate finite elements, numerical methods, thermodynamics, statistical mechanics, plasma fundamentals and gas dynamics.

\section{Bradley S. Davidson, University of Denver}

Dr. Bradley Davidson is an Assistant Professor in Mechanical Engineering and director of the Human Dynamics Laboratory at the University of Denver and Clinical Assistant Professor at the University of Colorado Anschutz Medical Campus. He holds a BS in civil engineering from Tennessee Tech, an MS in engineering mechanics from Virginia Tech, and a PhD in biomedical engineering from the Virginia Tech-Wake Forest School of Biomedical Engineering and Sciences. His research focuses on understanding and characterizing human movement across healthy and pathologic populations through in vivo experimental measurement and musculoskeletal modeling. Applications focus on fall prevention, spine stability, rehabilitation after total joint surgery, and muscle coordination and proprioception in the lumbo-pelvic region.

\section{Prof. Peter J. Laz, University of Denver}

Peter Laz is a Professor in Mechanical and Materials Engineering at the University of Denver. His research is in the area of probabilistic analysis related to orthopedic implants and structural components. He has been an investigator on industrial, federal (NSF, NIH) and foundation grants and written 35 journal papers and 100+ conference publications. He received his Bachelor's degree in mechanical engineering from Duke University and his MS and $\mathrm{PhD}$ degrees in mechanical engineering from Purdue University. $\mathrm{He}$ was a Fulbright scholar in Germany and also worked at Southwest Research Institute before joining the faculty at DU in 2001. 


\title{
Novel Sophomore Assessment Modeled after the FE Exam
}

\begin{abstract}
During the last quarter of the sophomore year, all students in the Departments of Mechanical and Materials Engineering (MME) and Electrical and Computer Engineering (ECE) at the University of Denver (DU) take an assessment exam. The purpose of this exam is to measure the knowledge of these students in the fields of basic math and science, as well as sophomore year engineering courses, such as digital design, statics, circuits, and mechanics of materials.
\end{abstract}

The students take the exam as part of a zero-credit course and the exam is given in two parts on separate days. The exam problems are similar to the Fundamentals of Engineering Exam (FE) problems, and students are only allowed to use the official FE Reference Handbook during the test. To pass the course students must score a combined average of $50 \%$ or better on both exams. If a student fails to reach this average on the exams, they are required to retake the course and obtain a passing score before they graduate. On average around $95 \%$ of students pass on the first attempt, and, to date, all have passed on a subsequent attempt.

The results of the exam are used in the internal assessment process of the MME Department. The results of the exam allow faculty to observe how well the students understand the fundamental building blocks that they will later use in more complex engineering problems during their upper divisional years. The exam also provides a checkpoint to see how well students are prepared to take the FE during their last year of study. And lastly, data from the exam allow for analysis of individual subjects and questions, allowing for exploration of how well students understand each subject tested, as well as individual topics.

Overall, our faculty has found the sophomore exam to be a helpful tool in assessing both the knowledge of our students, as well as the effectiveness of some of our early engineering courses. The MME department also requires that all students take the FE exam to graduate, giving a set of assessment data at two different time points in their career as a student.

Introduction

Successful assessment of undergraduate engineering programs is considered a key to moving a program forward, and avoiding the pursuit of ineffective paths that lead to a loss of time and energy by educators ${ }^{1}$. In fact, the 2016-2017 Accreditation Board for Engineering and Technology (ABET) Criteria for Accrediting Engineering Programs states: "The program faculty must have appropriate qualifications and must have and demonstrate sufficient authority to ensure the proper guidance of the program and to develop and implement processes for the evaluation, assessment, and continuing improvement of the program." ${ }^{2}$ Multiple assessment tools are popular for different programs and include interviews, surveys, focus groups, course evaluation data, standardized testing, and post-graduate analysis ${ }^{3,4}$. The variety of tools allows for each program to use the assessment protocol deemed by the faculty and administration involved to be the most effective. 
The Fundamentals of Engineering Exam (FE) provides a standardized option to assess the knowledge of students at the time of graduation ${ }^{5}$. As indicated by Watson et al., the information given to programs by the National Council of Examiners for Engineers and Surveyors (NCEES) about their students' performance used to be limited to only anonymous pass/fail data ${ }^{6}$.

Fortunately, data from NCEES is now available to programs that breaks down not only pass/fail rates, but also provides the average student performance in each topic area ${ }^{7}$. The Mechanical and Materials Engineering (MME) Department at the University of Denver requires that all students pursuing an undergraduate degree in Mechanical Engineering take the FE exam as part of their graduation requirements. This requirement allows for the data from the exam to be used by the department in the assessment process.

While the standardized FE exam was deemed helpful by the department during assessment, it was noted that the exam is completed at the end of a student's tenure, and it was desirable to gain information earlier in the student's career. This desire was based on the idea to track how well students had retained the basic math and science courses from their first two undergraduate years, and whether they were able to use this information to solve engineering problems. In order to do so, the School of Engineering developed a zero-credit course that was given at the end of the sophomore year. This course was originally developed in response to the ABET 2000 Criteria, and has been modified over the years to meet changes in protocol, curriculum, and technology ${ }^{8}$. During this course, the students go through an individual interview with the instructor and take an exam based on the courses from the first two years of the curriculum. This information is then used during the department's internal assessment process.

This paper gives an overview of this exam, as well as how it is used to help in our internal assessment process and outlines recent plans to use the exam to aid students in their upper divisional years as well. It also includes modifications that have occurred within the exam in the past years due to curriculum changes and changes to the FE exam itself.

\section{Sophomore Assessment Exam}

\section{Description of Exam}

All students in the departments of MME and Electrical and Computer Engineering (ECE) are required to take an assessment exam during the $3^{\text {rd }}$ quarter of their sophomore year as part of a zero credit course. The exam is given in two parts during the quarter, and the exams are roughly four weeks apart. Part one contains questions on topics of the basic math and science courses in the curriculum, which include: Chemistry, Physics, Algebra, Calculus, and Differential Equations. Part two covers questions on second year engineering courses, including: Digital Design, Circuits, Statics, Mechanics of Materials, Procedural Programming, and MATLAB. Each exam contains 70-80 multiple-choice questions that are all written in similar style to the FE exam. A few example questions are given below in Table 1: 
Table 1: Example questions and answers from the exam. Correct answers are indicated in bold

\begin{tabular}{|c|c|c|}
\hline Topic & Question & Multiple Choice Answers \\
\hline Physics/Calculus & $\begin{array}{l}\text { If } x=A \cos (w t), \text { what does velocity } \\
\text { equal? }\end{array}$ & $\begin{array}{l}\text { a) } A \cos w t \\
\text { b) }-A \cos w t \\
\text { c) }-A w \sin w t \\
\text { d) Aw sin wt } \\
\text { e) }-A w 2 \cos w t\end{array}$ \\
\hline Chemistry & $\begin{array}{l}\text { Which of the following electron } \\
\text { configurations is correct for silicon } \\
\text { (atomic number 14)? }\end{array}$ & $\begin{array}{l}\text { a) } 1 \mathrm{~s} 22 \mathrm{~s} 22 \mathrm{p} 63 \mathrm{~s} 13 \mathrm{p} 3 \\
\text { b) } 1 \mathrm{~s} 22 \mathrm{~s} 22 \mathrm{p} 63 \mathrm{~s} 43 \mathrm{p} 4 \\
\text { c) } 1 \mathrm{~s} 22 \mathrm{~s} 22 \mathrm{p} 63 \mathrm{~s} 23 \mathrm{p} 4 \\
\text { d) } 1 \mathrm{~s} 22 \mathrm{~s} 22 \mathrm{p} 63 \mathrm{~s} 23 \mathrm{p} 2 \\
\text { e) } 1 \mathrm{~s} 22 \mathrm{~s} 22 \mathrm{p} 63 \mathrm{~s} 43 \mathrm{p} 2\end{array}$ \\
\hline $\begin{array}{l}\text { Mechanics of } \\
\text { Materials }\end{array}$ & $\begin{array}{l}\text { A steel shaft of } 200 \mathrm{~mm} \text { diameter is } \\
\text { twisted by a torque of } 125.6 \mathrm{kNm} \text {. What } \\
\text { is the maximum shear stress in the } \\
\text { shaft? }\end{array}$ & $\begin{array}{l}\text { a) } 86 \mathrm{MPa} \\
\text { b) } 110 \mathrm{MPa} \\
\text { c) } 160 \mathrm{MPa} \\
\text { d) } 190 \mathrm{MPa} \\
\text { e) None of the above }\end{array}$ \\
\hline
\end{tabular}

The students take the exam on their personal computers through an internal assessment website. Students are given three hours to take each exam and they are allowed to use an FE-approved calculator along with the current edition of the FE Handbook, which they must download personally from the NCEES website.

In order to pass the exam the students must receive a combined average of $50 \%$ or better on both exams. The passing score of $50 \%$ was chosen to encourage students to try (i.e. not just fill in ' $\mathrm{C}$ ' the entire exam), but also allow the students to take the exam without studying, which was felt to lead to more accurate results for assessment purposes. While the class is worth zero credits, the students do receive a grade based on their combined average score on the two exams. The scale is as follows: $<50 \% \mathrm{~F} ; 50-59 \% \mathrm{C} ; 60-69 \% \mathrm{~B} ; 70-100 \% \mathrm{~A}$. While the grade does not affect the student's GPA, it does appear on their transcripts, giving incentive for them to put forth an effort.

Exam Results and Assessment

After students have completed the exam, a report is generated with data from the results, which includes the score of each student, as well as, their answer for each question. The overall exam results for the past three years are given in Table 2: 
Table 2: Overall pass rates of the exam for the past three years.

\begin{tabular}{|l|l|l|l|}
\hline Year & Number of Examinees & Total Exam Average & Pass Rate \\
\hline 2013 & 40 & $65 \% \pm 9 \%$ & $95 \%$ \\
\hline 2014 & 38 & $63 \% \pm 8.9 \%$ & $95 \%$ \\
\hline 2015 & 51 & $61 \% \pm 7.6 \%$ & $92 \%$ \\
\hline
\end{tabular}

The pass rate has been around $95 \%$ for most years, and all students that failed (score less than an average combined score of 50\%) passed when repeating the course. Assessing changes in the overall pass rates have allowed our department to look for specific areas that a specific class may have a weakness in, whether this is a specific course or even a cultural change. For example, in 2015 there was a $134 \%$ increase in the size of the sophomore year engineering class. At a program where most second year engineering courses are usually around 40 students, an increase in class size by over 10 students may have led to changes in the way the class was taught or the ability for the instructor to cover topics as efficiently as in previous years. A chi-square test run of the pass/fail data found that the difference in the pass rate was not significant ( $\mathrm{p}$-value $=0.86$ ). However, the change was noted as something to continue observing, especially because the size of the engineering classes has continued to grow in recent years. The current sophomore and freshman academic classes each have around 85 students, nearly doubling the size of recent classes. If it is found that the number of students is affecting the efficiency of courses it is necessary to deal with these changes promptly.

These data can also be employed to show how well the group of students performed on each question, as well as each individual topic or overall subject. Results of how many students answered an individual question correctly are available along with the subject of the question. It is therefore possible to see how a class performed on an overall subject, and on each question within that subject. This allows for the breakdown of specific topics that might not have been either taught effectively in a course or understood by the student cohort.

For example, it was noticed that students had a slight drop in performance in the statics section of the exam. The exam had nine questions about statics and the students scored an average of $49 \%$ on this section in 2014 and an average of $40 \%$ in 2015 . Because there was a change in instructor during this time it was of interest to observe how the students performed on each question and therefore different topics. A graph of this outcome data is shown in Figure 1. 


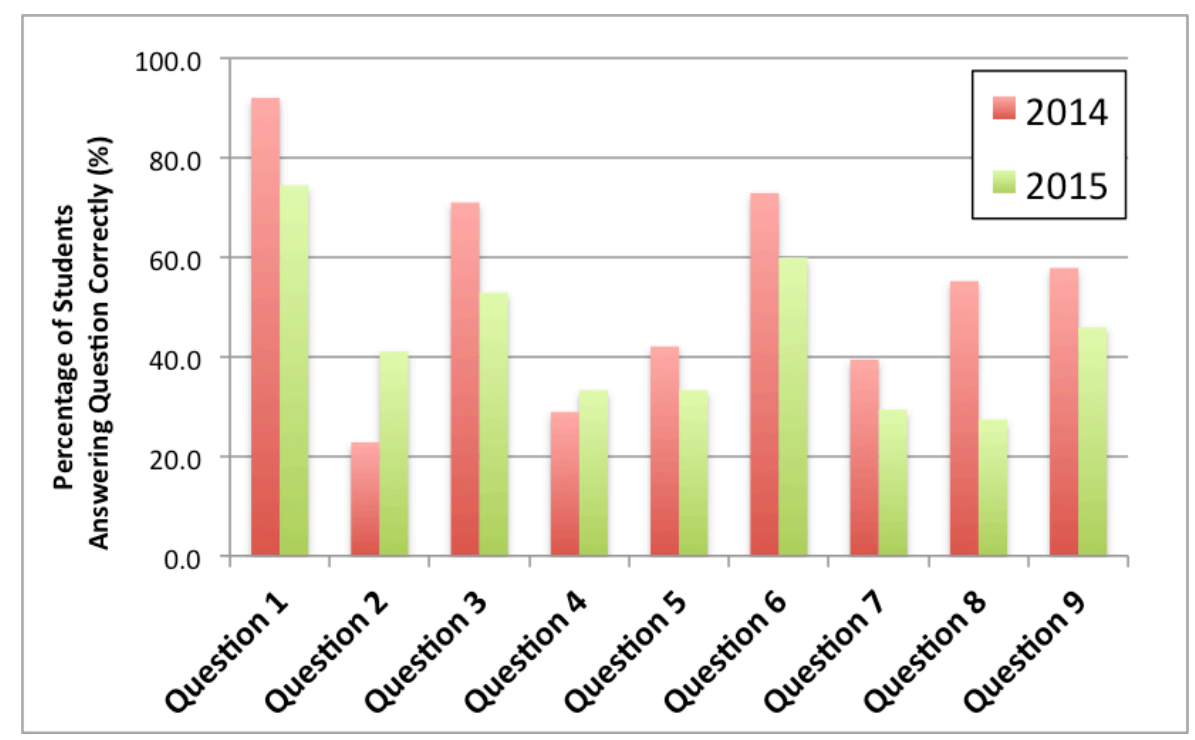

Figure 1: Graph showing the difference in percentages of students correctly answering the same questions between two academic years.

As can be observed in Figure 1, it is apparent that there was a drop in performance in almost all questions, except for Questions 2 and 4. These data would indicate that there was not one specific topic that was a problem for students, but the change could be due to a change in teaching style or, as stated previously, the increased number of students in the course in 2015. It is also possible that the class was simply not as strong in 2015 and therefore did not perform as well as previous years.

Data, such as those shown in Figure 1, help the faculty to observe trends in the understanding of specific subjects and topics during each year. These data allow for reflections on how students are performing on each class subject, as well as give the instructor of that subject specifics about what topics might be causing difficulty. It also allows for identification of questions that might not properly assess knowledge of a specific topic.

Outcomes from the sophomore exam and FE exam can also be used in conjunction with one another. One question posed while observing results from the sophomore exam was whether these results projected to the eventual performance of students on the FE exam. In order to observe this, it was decided to consider the results from the math section, as students are usually finished taking the full series of math classes by the end of their sophomore year. An average of all math questions (algebra through differential equations) from the past three sophomore exams was calculated to be $69 \pm 2 \%$ and an average of the math section from the past three FE exam results was calculated to be $72 \pm 2 \%$. These results suggested that the sophomore exam was a good comparator for future results of the FE examination for this topic. One limitation that should be noted is that the data available for this calculation did not match the exact students taking both exams and is therefore a cross-sectional comparison, not a predictor. This is because only MME students are required to take the FE exam, while all engineering students are required to take the sophomore exam. 
A second comparison was done with the statics sections of both exams. The average score from the sophomore exams was $48 \pm 4 \%$ while the $\mathrm{FE}$ average was $67 \pm 4 \%$. This variation in results suggests that the exam may not be the best predictor for outcome on this specific subject. While it is not easy to locate the exact reason for the disparity between outcomes several theories have been considered. One theory is that the questions on the sophomore exam may not necessarily match the difficulty on the FE exam. Another theory is perhaps student's problem solving skills improve as they practice solving engineering problems during their upperclassman years, making them more skilled at figuring out the solutions to problems in general. The latter theory could also be used in conjunction with the idea that since students continually use skills from subjects such as statics during their upperclassman years, they are gaining knowledge in this subject area even after they complete the course their sophomore year.

Besides using results from the Sophomore Assessment Exam to assess curriculum within the department, these results are also used in the annual assessment report for the MME Department submitted to the university. Both the results for the total exam scores (the average of both exams) and the score of the math section are utilized. For the total exam, the scores are ranked from 1-4 using the conversion: $1<50 \%, 2>50 \%, 3>60 \%, 4>70 \%$. Scores for the math portion only are assigned as follows: $1<55 \%, 2>55 \%, 3>60 \%, 4>75 \%$. These values are averaged and compared year to year for the assessment report. This assessment allows for examination of any significant variances in each year. If a drop in an average is noticed the assessment committee looks for areas of weakness that may have led to the change and makes suggestions to help improve this weakness.

\section{Exam Changes}

While the Sophomore Assessment Exam has been used for almost 20 years, changes to both the $2^{\text {nd }}$ year engineering curriculum, as well as the FE exam itself have led to modifications.

The Ritchie School of Engineering at DU is unique in that all undergraduate engineering students, regardless of major, take a common curriculum for the first five quarters ${ }^{9}$. This commonality means that students take the same basic math and science courses, as well as the same first two quarters of second year engineering courses. These courses match those used in the sophomore assessment exam. Three years ago some of the common engineering courses changed during the last quarter of the sophomore year. For example Mechanical Engineering majors are now no longer required to take a second circuits course, and Computer and Electrical Engineering majors are no longer required to take thermodynamics. These new course requirements led to changes in the assessment exam, including taking out subjects that were no longer shared and adding questions to the remaining courses. This change has also allowed for the exam to be more focused on a select set of courses that still describe the overall experience the students have during their first two years.

It should also be noted that the FE exam itself changed format in the past few years. Traditionally all examinees took the FE exam on one of two dates offered during the year (one in fall and one in spring). This exam was handwritten and split into two parts: a common morning section and a major specific afternoon section. The FE has since moved to a computer-based 
exam that is given at exam centers anytime during eight months of the year. To mimic the FE, the sophomore exam was also shifted to a computer based examination system.

\section{Additional Assessment Goals}

While exam results have proved useful to the department for assessing courses given prior to the end of the sophomore year, a new goal developed in recent years is to use the information to help students as they move into their junior and senior years. Quite often a limitation to assessment data is that it becomes available after students have already taken a course, or even after they have already graduated. Therefore often the changes implemented due to the assessment affect future students, but do not help the students that were assessed. The sophomore exam provides an opportunity for faculty to perform corrective action in junior year courses to aid in weaknesses found while analyzing the exam results.

An example of this corrective action happened in the fall of 2015 during the junior year fluid mechanics course. The instructor, who had access to the assessment results, noticed that the students in the course had a slight reduction in score for the differential equation questions on the sophomore exam. The instructor took the opportunity to test the students on differentials during equation derivations, and noticed that they did indeed appear to lack some knowledge. The instructor then decided to give a lesson on the math needed to derive the equations, where normally this math may have been skipped over to save time. On the subsequent homework, the students performed well when required to use these math skills to derive momentum equations. While this example is more anecdotal versus quantitative it gives a starting point for which corrective action items may be performed in the future to help students in upper divisional courses.

One plan for future years is to track student performance in specific subjects and inform instructors of junior year courses of the results. For example, if results from the exam showed a significantly less than average performance in a specific subject, such as statics, the professor of the junior year course that uses statics as a prerequisite would be notified. This instructor could then decide whether or not they feel the need to augment the knowledge of the students by performing a review session at the start of their course, or supply materials to the students to help supplement specific topics from statics the instructor feels need to be well understood before moving on in the current course.

An additional plan for future years is to give the students their results, specifically letting them know how well they did on each subject section. This report could mimic that which students now receive after the FE exam, giving them their scores as well as a comparison to the averages. The idea would be that students could use this information and take the initiative to improve certain areas where their knowledge may be lacking. While not all students may take the initiative, giving them the option would be a good opportunity to help with the corrective actions described above on a personal level. 


\section{Conclusion}

Overall, the exam has been established by the MME Department at DU as a consistent and helpful tool in examining the overall knowledge of our second year students. It has also been used to examine specifics about certain courses and subjects and how changes in instructors, pedagogy, or even class size of such courses have affected the exam outcome. Ongoing goals include using the exam results to locate areas of weakness for specific academic classes and take action to improve their understanding of subject material necessary for them to perform well in upper divisional courses.

\section{Bibliography}

1. Olds, Barbara M., Barbara M. Moskal, and Ronald L. Miller. "Assessment in engineering education: Evolution, approaches and future collaborations." Journal of Engineering Education 94.1 (2005): 13-25.

2. Criteria for Accrediting Engineering Programs, Accreditation Board for Engineering and Technology (2015): 5.

3. Mazurek, David Francis. "Consideration of FE exam for program assessment." Journal of Professional Issues in Engineering Education and Practice 121.4 (1995): 247-249.

4. Leydens, Jon A., Barbara M. Moskal, and Michael J. Pavelich. "Qualitative methods used in the assessment of engineering education." Journal of Engineering Education- Washington 93.1 (2004): 65-72.

5. Nirmalakhandan, N., D. Daniel, and K. White. "Use of Subject - specific FE Exam Results in Outcomes Assessment." Journal of Engineering Education 93.1 (2004): 73-77.

6. Watson, John L. "An analysis of the value of the FE examination for the assessment of student learning in engineering and science topics." Journal of Engineering Education 87.3 (1998): 305-311.

7. Barrett, Steven F., Steadman, John. W., Whitman, David L. "Using the Fundamentals of Engineering (FE) Exam as an Outcomes Assessment Tool." National Council of Examiners for Engineering and Surveying (2015): 1-18.

8. DeLyser, Ron R., Marv Hamstad. "Outcomes based assessment and successful ABET accreditation at the University of Denver." $30^{\text {th }}$ ASEE/IEEE Frontiers in Education Conference T1A-1 (2000).

9. DeLyser, Ron R., Albert J. Rosa, John Mirth, andungho Kim. "Undergraduate engineering curricula revision at the University of Denver." Frontiers in Education Conference \#8a5.4 (1996). 